\title{
The Effects of Antidepressant Treatment in Prenatally Stressed Rats Support the Glutamatergic Hypothesis of Stress-Related Disorders
}

\author{
Jordan Marrocco, ${ }^{1}$ Marie-Line Reynaert, ${ }^{2,6}$ Eleonora Gatta, ${ }^{2,6}$ Cecilia Gabriel, ${ }^{3}$ Elisabeth Mocaër, ${ }^{3}$ Silvia Di Prisco, ${ }^{4}$ \\ Elisa Merega, ${ }^{4}$ Anna Pittaluga, ${ }^{4}$ Ferdinando Nicoletti, ${ }^{5,6}$ Stefania Maccari, ${ }^{2,6}$ Sara Morley-Fletcher, ${ }^{2,6 *}$ \\ and Jérôme Mairesse ${ }^{2,6 *}$ \\ ${ }^{1}$ Istituto di Ricovero e Cura a Carattere Scientifico, Centro Neurolesi “Bonino-Pulejo," Messina 98124, Italy, ${ }^{2}$ Neural Plasticity Team-Unité Mixte de \\ Recherche 8576 Centre National de la Recherche Scientifique/Université Lille 1, Department of Structural and Functional Glycobiology, F-59655 Villeneuve \\ d'Ascq, France, ${ }^{3}$ Institutes de Recherches Internationales Servier, 92150 Suresnes, France, ${ }^{4}$ Department of Pharmacy, University of Genoa, Genoa 16146, \\ Italy, ${ }^{5}$ Sapienza University of Rome and Istituto di Ricovero e Cura a Carattere Scientifico Neuromed, Pozzilli 86077, Italy, and ${ }^{6}$ International Associated \\ Laboratory-Prenatal Stress and Neurodegenerative Diseases, F-59655 Villeneuve d'Ascq, IT-00185 Rome, IT-86077 Pozzilli
}

Abnormalities of synaptic transmission in the hippocampus represent an integral part of the altered programming triggered by early life stress, which enhances the vulnerability to stress-related disorders in the adult life. Rats exposed to prenatal restraint stress (PRS) develop enduring biochemical and behavioral changes characteristic of an anxious/depressive-like phenotype. Most neurochemical abnormalities in PRS rats are found in the ventral hippocampus, a region that encodes memories related to stress and emotions. We have recently demonstrated a causal link between the reduction of glutamate release in the ventral hippocampus and anxiety-like behavior in PRS rats. To confer pharmacological validity to the glutamatergic hypothesis of stress-related disorders, we examined whether chronic treatment with two antidepressants with different mechanisms of action could correct the defect in glutamate release and associated behavioral abnormalities in PRS rats. Adult unstressed or PRS rats were treated daily with either agomelatine (40 mg/kg, i.p.) or fluoxetine $(5 \mathrm{mg} / \mathrm{kg}$, i.p.) for $21 \mathrm{~d}$. Both treatments reversed the reduction in depolarization-evoked glutamate release and in the expression of synaptic vesicle-associated proteins in the ventral hippocampus of PRS rats. Antidepressant treatment also corrected abnormalities in anxiety-/depression-like behavior and social memory performance in PRS rats. The effect on glutamate release was strongly correlated with the improvement of anxiety-like behavior and social memory. These data offer the pharmacological demonstration that glutamatergic hypofunction in the ventral hippocampus lies at the core of the pathological phenotype caused by early life stress and represents an attractive pharmacological target for novel therapeutic strategies.

\section{Introduction}

A growing body of evidence suggests that abnormalities in hippocampal glutamatergic transmission are involved in the pathophysiology of mood and anxiety disorders (Tordera et al., 2007;

\footnotetext{
Received Sept. 25, 2013; revised Nov. 9, 2013; accepted Dec. 3, 2013.

Author contributions: F.N., S.M., S.M.-F., and J. Mairesse designed research; J. Marrocco, M.-L.R., E.G., S.D.P., E. Merega, A.P., S.M.-F., and J. Mairesse performed research; J. Marrocco, M.-L.R., E.G., C.G., E. Mocaër, A.P., S.M.-F., and J. Mairesse analyzed data; J. Marrocco, C.G., E. Mocaër, F.N., S.M., S.M.-F., and J. Mairesse wrote the paper.

This study was supported by University of Lille 1 and the Sapienza University of Rome (Frame Agreement signed between the two universities on 15 February 2007), (entre National de la Recherche Scientifique and Institute Neuromed (Pozzilli, Italy) in the framework of the European Research Team (GDRE 691) "Early Programming of Modern Diseases," and by International Associated Laboratory-Prenatal Stress and Neurodegenerative Diseases. M.L.R. was supported by the Ministry of French Education. E.G. was supported by the Ministry of French Education and Fondation de France. J. Mairesse received a funding from Fondation pour la Recherche Médicale.

*S.M.-F. and J. Mairesse are co-last authors.

C.G. and E. Mocaër are employed by Servier. The other authors declare no competing financial interests.

Correspondence should be addressed to Prof. Stefania Maccari, LIA-Prenatal Stress and Neurodegenerative Diseases (PSND), North University of Lille, France, Neuroplasticity Team, CNRS UMR 8576/ UGSF, Structural and Functional Glycobiology Unit, Bâtiment (9, Avenue Mendeleiev, 59655 Villeneuve d'Ascq, France. E-mail: stefania.maccari@univ-lille1.fr.

DOI:10.1523/JNEUROSCI.4131-13.2014

Copyright $\odot 2014$ the authors $\quad 0270-6474 / 14 / 342015-10 \$ 15.00 / 0$
}

Ongür et al., 2008; Garcia-Garcia et al., 2009; Chen et al., 2010; Musazzi et al., 2010, 2013; Popoli et al., 2011).

We were able to demonstrate a direct relationship between hippocampal glutamate release and anxiety in rats subjected to prenatal restraint stress (PRS; Marrocco et al., 2012). PRS rats (i.e., the offspring of mothers exposed to repeated episodes of restraint stress during the last $10 \mathrm{~d}$ of pregnancy) are characterized by a prolonged corticosterone response to acute stress, and by neurochemical and behavioral abnormalities that are typically linked to depression and anxiety (Dugovic et al., 1999; Darnaudéry and Maccari, 2008; Zuena et al., 2008; Morley-Fletcher et al., 2011; Mairesse et al., 2013). We found large reductions in depolarization-evoked glutamate release and in the expression of synaptic vesicle-associated proteins in the ventral hippocampus of adult PRS rats. In these rats, pharmacological enhancement of glutamate release by local injection of a cocktail of $\mathrm{GABA}_{\mathrm{B}}$ and $\mathrm{mGlu} 2 / 3$ receptor antagonists in the ventral hippocampus was able to reverse anxiety-like behavior (Marrocco et al., 2012). This was the first evidence of a hypofunction of glutamatergic neurotransmission in the ventral hippocampus in a model of depres- 
sion and anxiety, which has predictive, face, and construct validity. Glutamatergic hypofunction has also been found in postmortem brain tissue from depressed subjects (Choudary et al., 2005; Bernard et al., 2011). Of note, exposure to acute or chronic stress in adult life results instead in enhanced glutamate release in the hippocampus (Popoli et al., 2011), suggesting that the age window of exposure is critical for the effect of chronic stress on glutamatergic transmission. The evidence that the ventral portion of the hippocampus specifically encodes memories related to stress and emotions (Fanselow and Dong, 2010) strengthens the relation between our findings in PRS rats and the pathophysiology of anxiety/depressive disorders.

To support the glutamatergic hypothesis of stress-related disorders, it becomes fundamental to demonstrate that drugs that are currently used in the treatment of anxiety/depressive disorders can correct the defect in glutamate release found in the ventral hippocampus of PRS rats. To address this question, we used fluoxetine and agomelatine, two antidepressants that display different mechanisms of action. Fluoxetine is a selective serotonin reuptake inhibitor, which is marketed for the treatment of major depression, panic disorders, and obsessive-compulsive disorders (Sommi et al., 1987; Stokes and Holtz, 1997). Agomelatine is approved for the treatment of major depression and acts as a mixed $\mathrm{MT}_{1} / \mathrm{MT}_{2}$ melatonergic receptor agonist $/ 5-\mathrm{HT}_{2 \mathrm{C}}$ receptor antagonist (de Bodinat et al., 2010). Preclinical and clinical evidence demonstrate that agomelatine is also effective in the treatment of anxiety (Millan et al., 2005; Tuma et al., 2005; Loiseau et al., 2006; Papp et al., 2006; Stein et al., 2008, 2012; Baldwin and Lopes, 2009; Kasper et al., 2010; Morley-Fletcher et al., 2011; Levitan et al., 2012).

We examined the glutamatergic synapse by measuring $\mathrm{K}^{+}$evoked glutamate release from superfused synaptosomes and by analyzing the synaptic expression of vesicle-associated membrane protein (VAMP) as a representative protein of the SNARE complex, and of proteins regulating the trafficking of synaptic vesicles, such as synapsins, munc-18, and Rab3A (see also Marrocco et al., 2012). We report that chronic systemic treatment with either fluoxetine or agomelatine corrects the glutamatergic hypofunction in the ventral hippocampus and the associated behavioral abnormalities in adult PRS rats.

\section{Materials and Methods Animals}

Forty nulliparous female Sprague Dawley rats (20 for control group and 20 for PRS group), weighing $\sim 250 \mathrm{~g}$, were purchased from Charles River and housed under standard conditions with a $12 \mathrm{~h}$ light/dark cycle. Females were individually housed overnight with a sexually experienced male rat, and vaginal smears were examined on the following morning. The day at which the smear was sperm positive was considered as embryonic day 0.

\section{Stress protocol}

Animals were subjected to PRS according to our standard protocol (Maccari et al., 1995; Morley-Fletcher et al., 2003). From day 11 of pregnancy until delivery, pregnant female rats were subjected to three stress sessions daily (45 min each), during which they were placed in transparent plastic cylinders and exposed to bright light. Only male offspring from litters containing 10-14 pups with a comparable number of males and females were used for the experiments. A maximum of one or two male pups was taken from each litter for each measure to remove any litter effects (Becker and Kowall, 1977; Chapman and Stern, 1979). All experiments followed the rules of the European Communities Council Directive 2010/63/EU of 22 September 2010. The local ethics committee approved the prenatal stress procedure.

\section{Antidepressant treatment}

Antidepressant drugs were dissolved in hydroxyethylcellulose (HEC; $1 \%$ suspension in distilled water). Rats were 3 months old at the beginning of the treatment. Control and PRS rats were treated daily over 3 weeks with intraperitoneal injections of fluoxetine $(5 \mathrm{mg} / \mathrm{ml} / \mathrm{kg}$; Sigma), agomelatine ( $40 \mathrm{mg} / 2 \mathrm{ml} / \mathrm{kg}$; Servier), or $1 \mathrm{ml} / \mathrm{kg}$ HEC alone (vehicle). The dose of agomelatine was selected on the basis of previous reports (Van Reeth et al., 1997; Papp et al., 2003; Banasr et al., 2006; Soumier et al., 2009) and on previous data obtained in the PRS rats (Morley-Fletcher et al., 2011). The dose of fluoxetine was administered according to the standard regimen described by Nibuya et al. (1996). Injections were performed $2 \mathrm{~h}$ before the onset of the dark phase of the $12 \mathrm{~h}$ light/dark cycle, based on the circadian rhythm resynchronization properties and antidepressant activity of agomelatine (Van Reeth et al., 1997; Papp et al., 2003).

All animals used for ex vivo measurements of neurotransmitter release and immunoblot analysis of protein expression had been tested for behavior at least 1 week earlier.

\section{Glutamate and GABA release experiments}

Purified synaptosomes isolated from the ventral hippocampus ( $n=5 \mathrm{per}$ group) were prepared essentially according to the procedures of Dunkley et al. (1986), with minor modifications. Briefly, the tissue was homogenized in 10 volumes of $0.32 \mathrm{M}$ sucrose, buffered to $\mathrm{pH} 7.4$ with Tris (final concentration, $0.01 \mathrm{M}$ ) using a glass Teflon tissue grinder (clearance, 0.25 $\mathrm{mm}$ ). The homogenate was centrifuged at $1000 \times g$ for $5 \mathrm{~min}$ to remove nuclei and debris; the supernatant was gently stratified on a discontinuous Percoll gradient $(6 \%, 10 \%$, and $20 \% \mathrm{v} / \mathrm{v}$ in Tris-buffered sucrose) and centrifuged at $33,500 \times g$ for $5 \mathrm{~min}$. The layer between $10 \%$ and $20 \%$ Percoll (synaptosomal fraction) was collected and washed by centrifugation. The synaptosomal pellet was then resuspended in physiological medium (standard medium) having the following composition (in $\mathrm{mM}$ ): $\mathrm{NaCl} 140 ; \mathrm{KCl} 3 ; \mathrm{MgSO}_{4}$ 1.2; $\mathrm{CaCl}_{2}$ 1.2; $\mathrm{NaH}_{2} \mathrm{PO}_{4} 1.2 ; \mathrm{NaHCO}_{3}$ 5; HEPES 10; and glucose 10; $\mathrm{pH} 7.2-7.4$. Synaptosomes were incubated for $15 \mathrm{~min}$ at $37^{\circ} \mathrm{C}$ in a rotary water bath and superfused at $0.5 \mathrm{ml} / \mathrm{min}$ with standard physiological solution. When studying the release of neurotransmitter evoked by high concentrations of $\mathrm{K}^{+}$, synaptosomes were transiently (90 s) exposed, at $t=39 \mathrm{~min}$, to $12 \mathrm{~mm} \mathrm{KCl}$ (substituted for $\mathrm{NaCl}$ in the superfusate). Superfusion was always performed with media containing $50 \mu \mathrm{M}$ amino-oxyacetic acid (Sigma) to inhibit GABA metabolism. Three superfusate fractions were collected according to the following scheme: two $3 \mathrm{~min}$ fractions (basal release), one before $(t=36-39$ $\min$; b1) and one after $(t=45-48 \mathrm{~min}$; b3) a 6 min fraction $(t=39-45$ min; evoked release, b2). Fractions collected and superfused synaptosomes were counted for endogenous amino acid content. Endogenous glutamate and GABA were measured by HPLC analysis after pre-column derivatization with $o$-phthalaldehyde and separation on a C18 reversephase chromatographic column $\left(10 \times 4.6 \mathrm{~mm}, 3 \mu \mathrm{m}\right.$; at $30^{\circ} \mathrm{C}$; Chrompack) coupled to fluorimetric detector (excitation wavelength, $350 \mathrm{~nm}$; emission wavelength, $450 \mathrm{~nm}$ ). Buffers and the gradient program were as follows: solvent $\mathrm{A}, 0.1 \mathrm{M}$ sodium acetate, $\mathrm{pH}$ 5.8/methanol, 80:20; solvent $\mathrm{B}, 0.1 \mathrm{M}$ sodium acetate, $\mathrm{pH}$ 5.8/methanol, 20:80; solvent C, 0.1 M sodium acetate, $\mathrm{pH}$ 6.0/methanol, 80:20; gradient program, $100 \% \mathrm{C}$ for $4 \mathrm{~min}$ from the initiation of the program; $90 \% \mathrm{~A}$ and $10 \% \mathrm{~B}$ in $1 \mathrm{~min}$; isocratic flow, $2 \mathrm{~min} ; 78 \%$ solvent $\mathrm{A}$ and $22 \%$ solvent $\mathrm{B}$ in $2 \mathrm{~min}$; isocratic flow, $6 \mathrm{~min}$; $66 \%$ solvent $\mathrm{A}$ and $34 \%$ solvent B in $3 \mathrm{~min} ; 42 \%$ solvent A and 58\% solvent B in $1 \mathrm{~min} ; 100 \%$ solvent B in $1 \mathrm{~min}$; isocratic flow, $2 \mathrm{~min} ; 100 \%$ solvent $\mathrm{C}$ in $3 \mathrm{~min}$; flow rate, $0.9 \mathrm{ml} / \mathrm{min}$. Homoserine was used as the internal standard. Synaptosomal protein contents were determined according to Bradford (1976). The amount of endogenous glutamate and GABA from synaptosomes in superfusate fractions was expressed as picomoles per milligram of protein. The depolarizationinduced overflow was estimated by subtracting the neurotransmitter content into the first and the third $3 \mathrm{~min}$ fractions collected (basal release, b1 and b3) from that in the 6 min fraction collected during and after the depolarization pulse (evoked release, b2).

\section{Western blot analysis}

Control and PRS rats ( $n=4$ per group) were killed by decapitation, and dorsal and ventral hippocampi were rapidly dissected and immediately 

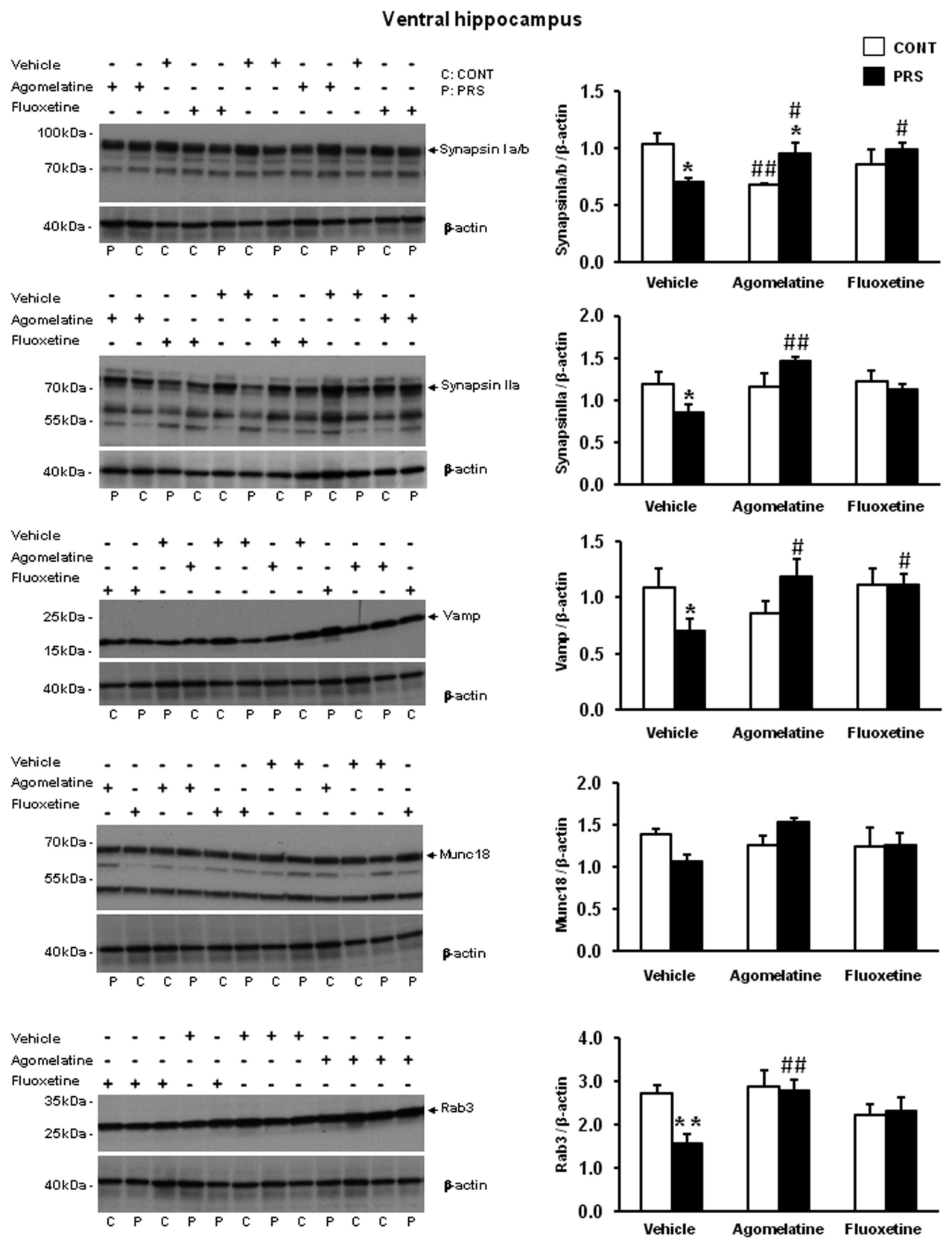

Figure 1. Chronic treatment with agomelatine or fluoxetine corrects abnormalities in the expression of synaptic vesicle-associated proteins in the ventral hippocampus of PRS rats. Control unstressed rats (CONT) and PRS rats were treated intraperitoneally with vehicle, agomelatine $(40 \mathrm{mg} / \mathrm{kg})$, or fluoxetine $(5 \mathrm{mg} / \mathrm{kg})$ for $21 \mathrm{~d}$. Representative continuous, uncropped images of 12 sample immunoblots ( 2 samples per group per treatment) are shown on the left side ( $C$, control unstressed rats; $P, P R S$ rats). Values are given as the mean $\pm S E M\left(n=4\right.$ rats per group). ${ }^{*} p<0.05$ or ${ }^{* *} p<0.01$ vs the respective CONT rats; $\# p<0.05$ or \#\#p $<0.01$ vs vehicle-treated CONT or PRS rats.

stored at $-80^{\circ} \mathrm{C}$. Immunoblotting analysis was performed on the synaptosomes isolated from the ventral hippocampus. To isolate synaptosomes, tissue was manually homogenized with a potter in 10 volumes of HEPES-buffered sucrose (0.32 $\mathrm{m}$ sucrose, $4 \mathrm{~mm}$ HEPES $\mathrm{pH} 7.4)$. All procedures were performed at $4^{\circ} \mathrm{C}$. Homogenates were centrifuged at $1000 \times g$ for $10 \mathrm{~min}$, and the resulting supernatants were centrifuged at $10,000 \times g$ for $15 \mathrm{~min}$. The pellet obtained from the second centrifugation was resuspended in 10 volumes of HEPES-buffered sucrose and then spun again at $10,000 \times g$ for $15 \mathrm{~min}$. This pellet contained the crude synaptosomal fraction. To validate the purity of this synaptosomal fraction, we used anti-histone $\mathrm{H} 3$, anti- $\beta$-tubulin, and anti-synapsin Ia/b in immunoblot analysis. BCA assay was used to determine protein concentration. Synaptosome lysates were resuspended in Laemmli reducing buffer, and $20 \mu \mathrm{g}$ of each sample was first separated by electrophoresis on Criterion TGX $4-15 \%$ precast SDS-PAGE gels (26 wells; Bio-Rad) and later transferred to nitrocellulose membranes (Bio-Rad). Transfer was performed at $4^{\circ} \mathrm{C}$ in a buffer containing $35 \mathrm{~mm}$ Tris, $192 \mathrm{~mm}$ glycine, and $20 \%$ methanol.

We used the following primary antibodies: rabbit polyclonal antisynapsin Ia/b (1:4000; catalog \#sc-20780), rabbit polyclonal antisynapsin IIa (1:4000; catalog \#sc-25538) and rabbit polyclonal antiVAMP (1:2000; synaptobrevin; catalog \#sc-13992), all purchased from Santa Cruz Biotechnology; mouse monoclonal anti-rab3a (1:2000; cata$\log \# 107111)$ and mouse monoclonal anti-Munc-18 (1:2000; catalog \#116011), which were purchased from Synaptic Systems. All primary antibodies were incubated overnight at $4^{\circ} \mathrm{C}$. HRP-conjugated secondary anti-mouse or anti-rabbit antibodies (purchased from GE Healthcare) were used at a dilution of 1:10000 and were incubated for $1 \mathrm{~h}$ at room temperature. Densitometric analysis was performed with Quantity One software (Bio-Rad) associated with a GS-800 scanner. The ratio of indi- 
vidual proteins to $\beta$-actin was then determined, and these values were compared for statistical significance.

\section{Behavioral analysis}

Assessment of social memory

At day 15 of antidepressant treatment, the juvenile recognition abilities of the rats $(n=9$ per group) were assessed using the procedure described by Dantzer et al. (1987) and adapted as follows. During each of the three sessions (three sessions per day), a given juvenile rat (handled with rubber gloves) was introduced into the home cage of the adult rat for $5 \mathrm{~min}$ in a normally illuminated, quiet room during the light phase of the cycle (i.e., between 3:30 and 6:30 P.M.). Then, the juvenile was removed, kept individually in a cage $(39 \times 24 \times 16 \mathrm{~cm})$ with fresh bedding and food and water available ad libitum for a defined interexposure interval of 30 or $120 \mathrm{~min}$; it was then presented again to the adult for a 5 min period. Sessions were video recorded, and the times spent in sniffing (the tested animal sniffs the challenger's fur), grooming (licking behavior of the tested animal toward the challenger), anogenital interaction (the tested animal sniffs challenger's ano-genital zone), and play (the tested animal is in rearing position and interacts with anterior paws with the challenger) were measured by a trained observer (Observer 20, Noldus).

\section{Assessment of anxiety-like behavior}

Anxiety-like behavior was assessed on day 16 of chronic antidepressant treatment in the light and dark test as previously described (Marrocco et al., 2012). The light and dark box setup consisted of the following two compartments: one light compartment $(45 \times 32 \times 32 \mathrm{~cm} ; 50$ lux; light box) and one dark compartment $(30 \times 32 \times 32 \mathrm{~cm} ; 5$ lux $)$. The compartments were connected via a small opening $(10 \times 15$ $\mathrm{cm}$ ) enabling transition between the two boxes. Rats ( $n=9$ per group) were placed in the light compartment, and the time spent in each compartment and the latency to the first entry into the light compartment during the 5 min test were assessed on-line via a video camera located above the box. Behavior was automatically analyzed using video-tracking software (View Point).

\section{Assessment of depressive-like behavior}

Forced swim test. At day 18 of antidepressant treatment, rats $(n=9$ per group) were subjected to an adapted version of the forced swim test (Porsolt et al., 1978) in a cylindrical container (height, $59 \mathrm{~cm}$; diameter, $25 \mathrm{~cm}$ ) filled with water at $25^{\circ} \mathrm{C}$ up to a level of $36 \mathrm{~cm}$. The test was performed between 12:00 and 5:00 P.M. Twenty-four hours after a 15 min session (pretest, on day 15), control and PRS rats were tested (day 16) during a 5 min session, during which immobility latency and duration, climbing, and swimming were automatically analyzed using videotracking software (View Point).

Splash test. At day 19 of treatment, a separate set of animals $(n=6-8$ per group) underwent an adapted version of the splash test (Santarelli et al., 2003; Yalcin et al., 2005; Surget et al., 2008). Briefly, the test consisted of spraying a $10 \%$ sucrose solution on the rat in a familiar cage. The sucrose solution dirtied the coat and induced a grooming behavior. After applying sucrose solution, the time spent grooming was recorded for 5 min as an index of self-care and motivational behavior. Previous works in mice have shown that in the splash test, chronic stress decreases groom-

\section{Glutam ate}

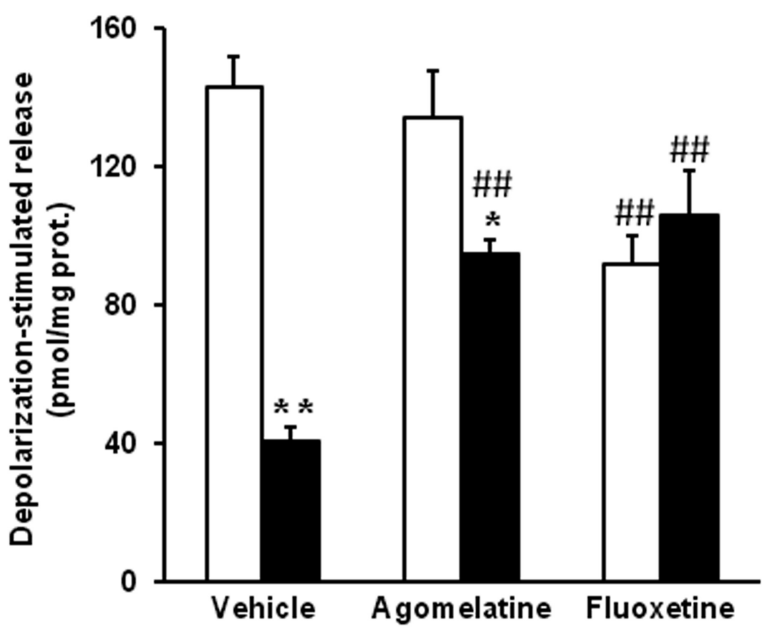

GABA

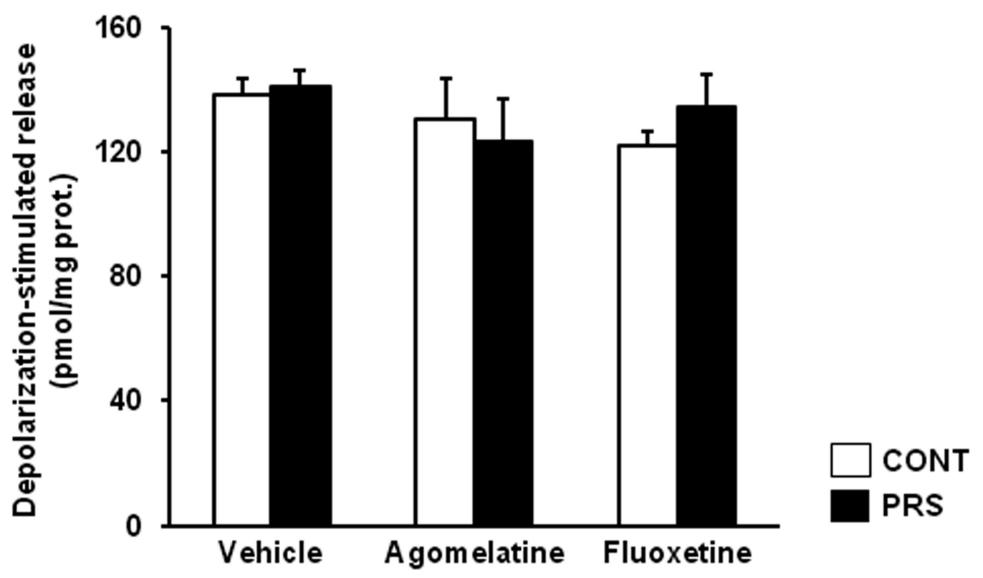

Figure 2. Chronic treatment with agomelatine or fluoxetine largely restores glutamate release in synaptosomes prepared from synaptosomes prepared from control unstressed rats (CONT) and PRS rats treated with vehicle, agomelatine $(40 \mathrm{mg} / \mathrm{kg}$ ), or fluoxetine $(5 \mathrm{mg} / \mathrm{kg})$ for $21 \mathrm{~d}$. Values are given as the mean \pm SEM ( $n=5$ rats per group). ${ }^{*} p<0.05$ or ${ }^{* *} p<0.01$ vs the respective CONT rats; \#\#p $<0.01$ vs vehicle-treated CONT or PRS rats.

ing behavior, a form of motivational behavior considered to parallel apathetic behavior as a symptom in depression (Isingrini et al., 2010). Moreover, stress-induced grooming perturbation is associated with reduced hedonic reactivity in the sucrose preference test and increased immobility in the forced swim test (Pothion et al., 2004; Isingrini et al., 2010).

\section{Statistical analysis}

Data were analyzed by two-way ANOVA (group by treatment) with the exception of data on social memory, which were analyzed by three-way ANOVA for repeated measures (group $\times$ treatment $\times$ interval). The Fisher's least significant difference post hoc test was used to isolate the differences. Correlations were analyzed using the Pearson's correlation analysis. A $p$ value $\leq 0.05$ was considered to be statistically significant.

\section{Results}

Chronic treatment with antidepressants reverses the changes in synaptic vesicle proteins and the ensuing defect in glutamate release in the ventral hippocampus of PRS rats We measured the levels of synaptic vesicle proteins in purified synaptosomal membranes prepared from the ventral hippocam- 


\section{Light-dark test}

\section{A}
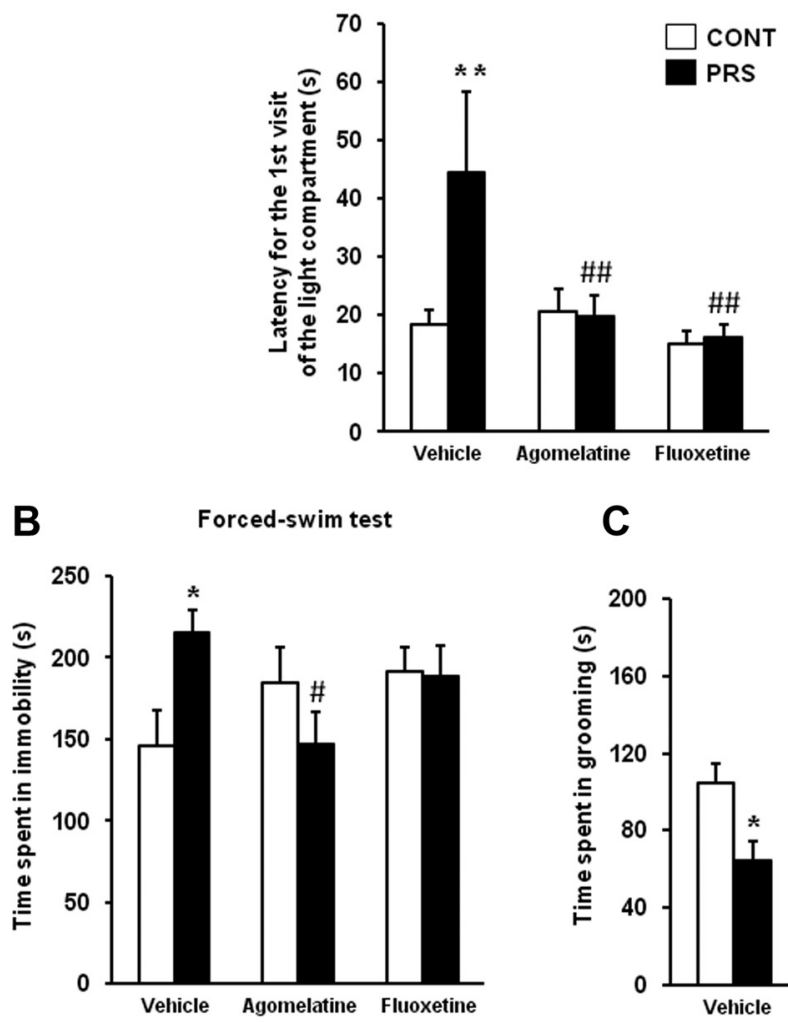

C

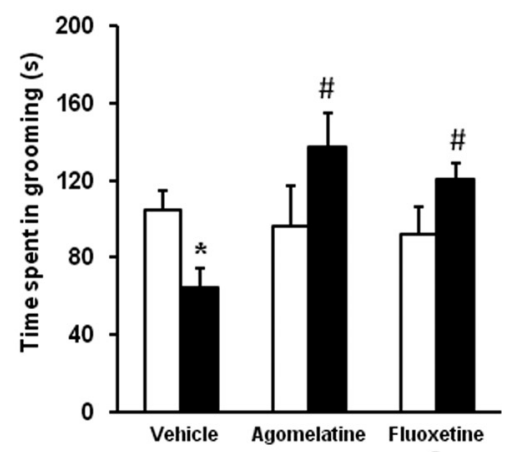

Figure 3. Chronic treatment with agomelatine or fluoxetine corrects anxiety- and depression-like behaviors in PRS rats. $\boldsymbol{A}, \boldsymbol{B}$, The same groups of rats used for the assessment of glutamate release were examined in the light-dark box $(A)$, and in the forced swim test $(\boldsymbol{B})$, as indicated in the Methods session. Different groups of rats were tested in the splash test $(\boldsymbol{C})$. Control unstressed rats (CONT) and PRS rats were treated intraperitoneally with vehicle, agomelatine $(40 \mathrm{mg} / \mathrm{kg})$, or fluoxetine $(5 \mathrm{mg} / \mathrm{kg})$ for $21 \mathrm{~d}$. Values are given as the mean $\pm \operatorname{SEM}$ ( $n=9$ rats per group). ${ }^{*} p<0.05$ or ${ }^{* *} p<0.01$ vs the respective CONT rats; $\# p<0.05$ or \#\#p $<$ 0.01 vs vehicle-treated CONT or PRS rats.

pus of control and PRS rats. PRS rats treated with vehicle for $21 \mathrm{~d}$ showed significant reductions in the levels of synapsin $\mathrm{Ia} / \mathrm{b}$ (group $\times$ treatment, $F_{(2,18)}=6.87, p<0.01$ ), synapsin IIa (group $\times$ treatment, $\left.F_{(2,18)}=4.25, p<0.05\right)$, VAMP (synaptobrevin; group $\times$ treatment, $\left.F_{(2,18)}=3.55, p=0.05\right)$, and Rab3A (group $\times$ treatment, $\left.F_{(2,18)}=3.54, p=0.05\right)$, and a trend to a reduction in munc18 compared with control unstressed rats treated with vehicle (Fig. 1; see also Marrocco et al., 2012). Chronic treatment with either agomelatine $(40 \mathrm{mg} / \mathrm{kg} / \mathrm{d}$, i.p.) or fluoxetine $(5 \mathrm{mg} / \mathrm{kg} / \mathrm{d}$, i.p.) for $21 \mathrm{~d}$ normalized the levels of synaptic vesicle-associated proteins in PRS rats. After agomelatine treatment, levels of synapsin Ia/b were higher in PRS than in control unstressed rats, but this was due to the lowering effect of agomelatine on synapsin $\mathrm{Ia} / \mathrm{b}$ in control rats. No main changes due to PRS or antidepressant treatment were observed in synaptic proteins in the dorsal hippocampus (data not shown). Glutamate and GABA release was measured in synaptosomes using a superfusion method that allows a clean estimation of $\mathrm{Ca}^{2+}$-dependent glutamate exocytosis without the components mediated by the endogenous activation of either presynaptic autoreceptors/heteroreceptors or membrane transporters (Raiteri et al., 1974; Raiteri and Raiteri, 2000; Bonanno et al., 2005). Synaptosomes prepared from the ventral hippocampus of unstressed control or PRS rats treated with vehicle, agomelatine, or fluoxetine were challenged with depolarizing concentrations of $\mathrm{K}^{+}$, and the superfusate was used for mea- surements of endogenous glutamate and GABA release. Basal glutamate release did not change as a function of groups (data are expressed as pmoles/milligram protein in the first and the third 3 min fractions; control rats treated with vehicle: $156.12 \pm$ 13.66; PRS rats treated with vehicle: $137.82 \pm 17.64$ ) or treatments (control rats treated with agomelatine: $147.54 \pm 17.5$; control rats treated with fluoxetine: $172.14 \pm 22.31$; PRS rats treated with agomelatine: $134 \pm 21.21$; PRS rats treated with fluoxetine: $154 \pm 12.37)$. In contrast, depolarization-evoked glutamate release (i.e., depolarization-induced overflow) was substantially reduced in hippocampal synaptosomes of PRS rats treated with vehicle, compared with the respective control group (ANOVA group $\times$ treatment, $F_{(2,24)}=$ $18.67, p<0.01$; Fig. $2 A$ ). This reduction was corrected in PRS rats treated with agomelatine and fluoxetine $(p<0.01)$. No difference in depolarization-evoked glutamate release was seen between PRS and control rats treated with fluoxetine. However, this datum is biased by the reduction of glutamate release found in control rats treated with fluoxetine $(p<0.01)$. Depolarizationevoked glutamate release was significantly higher in PRS rats treated with agomelatine or fluoxetine, compared with PRS rats treated with vehicle $(p<0.05)$. No changes in basal and depolarization-evoked GABA release were observed in control and PRS rats treated with vehicle or antidepressants (Fig. 2B).

Thus, chronic treatment with antidepressants normalizes both vesicle-associated proteins and depolarization-evoked glutamate release in the ventral hippocampus of PRS rats, with no or slight effect on control unstressed rats.

\section{Behavioral effects of agomelatine or fluoxetine treatments}

We used the light-dark test and the forced swim test for the assessment of anxiety-like behavior and depressive-like behavior in PRS rats (Morley-Fletcher et al., 2011; Marrocco et al., 2012). We also used the splash test for the assessment of self-care and hedonic behavior (Surget et al., 2008). In addition, we examined social recognition toward a juvenile rat as a test for social memory (Dantzer et al., 1987). The same groups of animals used for measurements of glutamate release underwent a social memory test at day 15 , anxiety-like behavior test at day 16 , and forced swim test at day 18 of drug treatment. A separate group of rats was used for the splash test at day 19 of treatment.

PRS rats treated with vehicle displayed an increased latency to enter the light compartment of the light-dark box, as expected. Both agomelatine and fluoxetine abolished differences in anxiety-like behavior between control and PRS rats (ANOVA, group $\times$ treatment, $F_{(2,48)}=4.95, p<0.05$; Fig. $\left.3 A\right)$. The action of agomelatine and fluoxetine diverged in the two tests used for the assessment of depressive-like behavior. In the forced swim test, agomelatine, but not fluoxetine, reduced the increased immobility time in PRS rats (ANOVA, group $\times$ treatment, $F_{(2,48)}=$ 
4.24, $p<0.05$; Fig. 3B). PRS rats showed reduced grooming behavior in the splash test, which reflects an impaired motivation, and treatment with both agomelatine and fluoxetine reversed this type of depressive-like behavior (ANOVA, group $\times$ treatment, $F_{(2,37)}=4.49, p<0.05$; Fig. $3 C$ ). Finally, we assessed cognitive social performance by examining the ability to recognize a juvenile challenger through three consecutive 5 min exposures. In unstressed control rats, sniffing behavior was reduced from the first to the second and third exposure to the intruder. Sniffing behavior was reduced to a lesser extent in PRS rats, and, again, this behavioral abnormality was corrected by treatments with fluoxetine or agomelatine (ANOVA, group $\times$ treatment $\times$ interval exposure, $F_{(4,96)}=2.51$, $p<0.05$; Fig. $4 A, B)$.

Thus, the effect of antidepressants on anxiety- and depression-like behaviors was "disease dependent," being selectively observed in PRS rats.

The anxiolytic action of agomelatine and fluoxetine is correlated to normalization of glutamate release We have recently reported that depolarization-evoked glutamate release in the ventral hippocampus is negatively correlated with anxiety-like behavior of PRS rats (Marrocco et al., 2012). All control and PRS rats used for measurements of glutamate release in synaptosomes ( $n=5$ rats per group) had been previously tested for anxietylike behavior in the light-dark box, and depressive-like behavior in the forced swim test and the social memory test (see above). We examined, for each animal in each group, the correlation between depolarization-evoked glutamate release in the ventral hippocampus and (1) the latency to enter the light box; (2) the immobility time in the forced swim test; and (3) the reduction in sniffing behavior at the second exposure to the juvenile challenger. In addition, we examined whether treatment with fluoxetine or agomelatine could affect these correlations. We found that depolarization-evoked glutamate release in the ventral hippocampus was negatively correlated with anxiety-like behavior, and the correlation was maintained when the analysis included rats treated with agomelatine and fluoxetine. In contrast, glutamate release showed a positive correlation with social memory performance only when rats treated with vehicle and agomelatine were included in the analysis. Depressive-like behavior in the forced swim test showed no apparent correlation with glutamate release in the ventral hippocampus. Finally, there was no correlation among the three different behaviors with the exception of a negative correlation between social memory performance and depressive-like behavior restricted to vehicle- and agomelatine-treated rats (Fig. 5; Table 1).

\section{Discussion}

We have shown that chronic treatment with two antidepressants endowed with different mechanisms of action (i.e., fluoxetine
Social memory
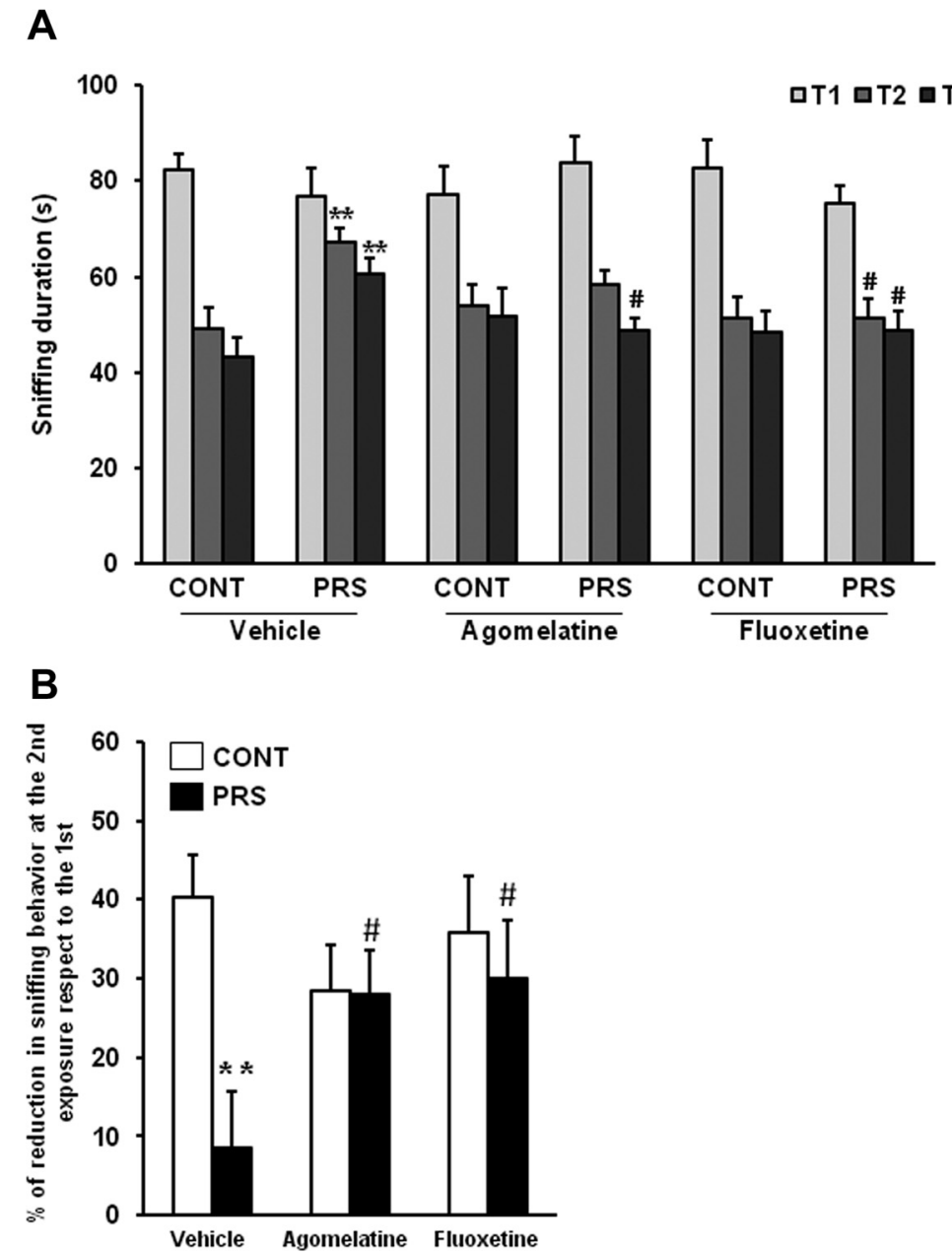

Figure 4. Chronic treatment with agomelatine or fluoxetine improves social memory in PRS rats. Control unstressed rats (CONT) (he first (T1), second (T2), and third (T3) exposure to the juvenile challenger are shown in $\boldsymbol{A}$. The percentage of reduction at the second exposure respect to the first is shown in $\boldsymbol{B}$. Values are means $\pm \mathrm{SEM}$ ( $n=9$ rats per group). ${ }^{* *} p<0.01$ vs the respective CONT rats; $\# p<0.05$ vs vehicle-treated CONT or PRS rats.

and agomelatine) reversed the reduction in depolarizationevoked glutamate release in the ventral hippocampus and corrected a range of pathological behaviors in PRS rats. These included anxiety-like behavior in the light-dark box; increased immobility time in the forced swim test; reduced grooming behavior in the splash test, reflecting low self-care; and reduced social memory performance toward a juvenile challenger. The effects of fluoxetine and agomelatine were similar, but not identical. In general, agomelatine showed a more complete profile than fluoxetine in correcting the neurochemical and behavioral abnormalities of PRS rats, with poor or no effects in unstressed control rats. In contrast, fluoxetine treatment abolished most of the differences between unstressed and PRS rats, but also caused a small but significant reduction of glutamate release in the ventral hippocampus of unstressed rats. Thus, at least in our model, agomelatine behaves as a "disease-dependent" drug, being selective for the pathological state (see also Morley-Fletcher et al., 2011). The lack of agomelatine effect in our control rats is in disagreement with recent findings showing that chronic agomelatine treatment reduces depolarization-evoked glutamate release in hippocampal synaptosomes of unstressed rats (Milanese 

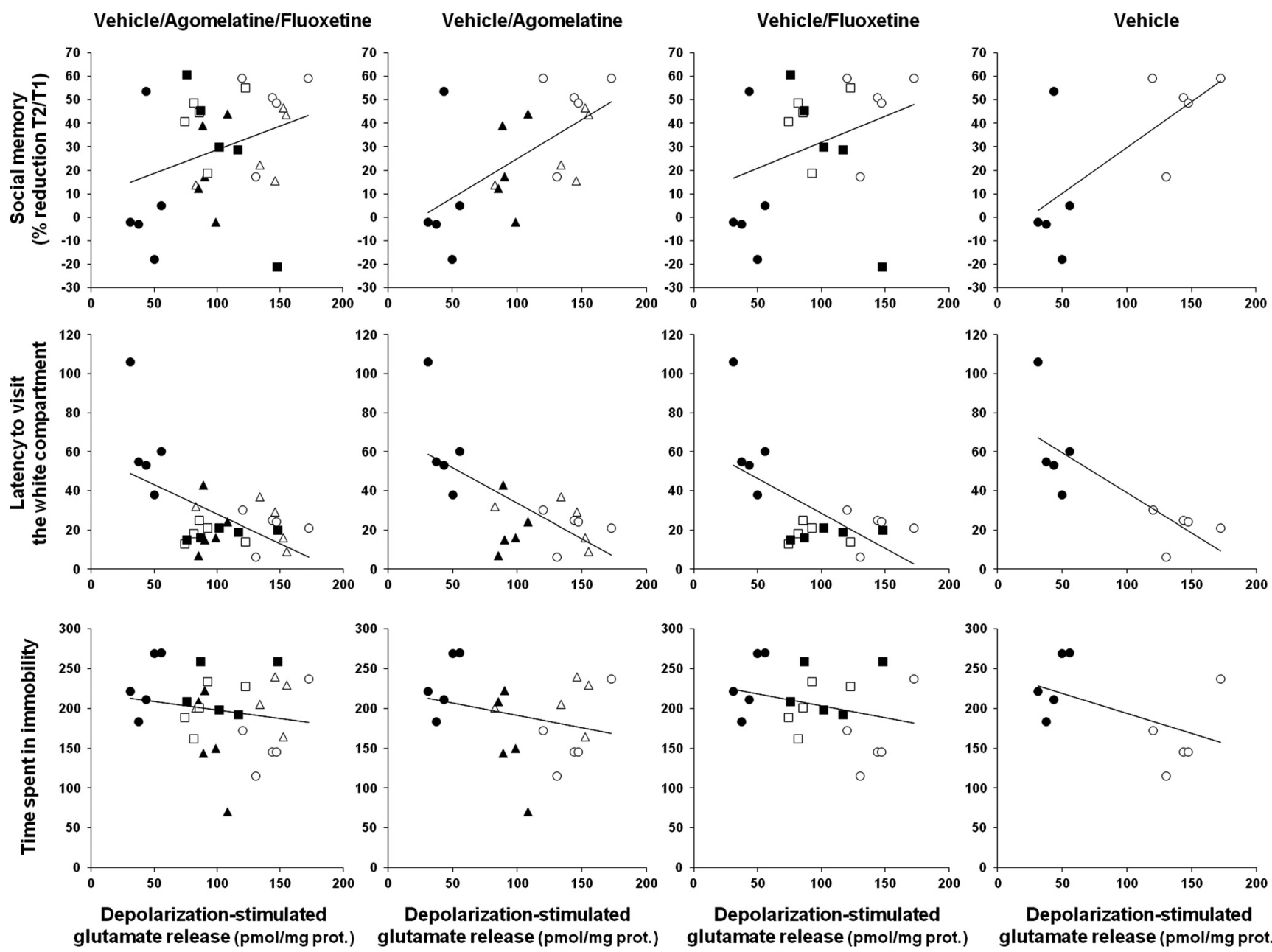

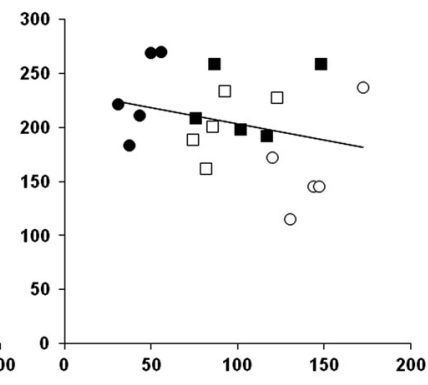

Depolarization-stimulated glutamate release (pmol/mg prot.)

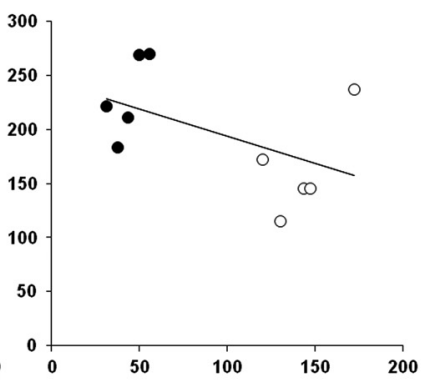

Depolarization-stimulated glutamate release (pmol/mg prot.)

\section{OCONT Vehicle $\triangle$ CONT Agomelatine $\quad \square$ CONT Fluoxetine}

PRS Vehicle

$\triangle$ PRS Agomelatine

PRS Fluoxetine

Figure 5. Correlation analysis of depolarization evoked glutamate release in the ventral hippocampus toward anxiety-like behavior in the light-dark box, depression-like behavior in the forced swim test, and social memory performance. Pearson's correlation coefficient ( $r$ ) values and related $p$ values are reported in Table 1 ( $n=5$ rats per group). CONT, Control unstressed rats.

Table 1. Statistical analysis of correlation data among depolarization-evoked glutamate release in the ventral hippocampus, anxiety-like behavior in the light-dark box, depression-like behavior in the forced-swim test, and social memory performance

\begin{tabular}{|c|c|c|c|c|c|c|c|c|}
\hline \multirow[b]{2}{*}{ Interactions } & \multicolumn{2}{|c|}{ Veh/Ago/Flx } & \multicolumn{2}{|l|}{ Veh/Ago } & \multicolumn{2}{|l|}{ Veh/Flx } & \multicolumn{2}{|l|}{ Veh } \\
\hline & $r$ value & $p$ value & rvalue & $p$ value & rvalue & $p$ value & $r$ value & $p$ value \\
\hline Glutamate release $\times$ social memory & 0.32 & 0.08 & $0.62^{*}$ & 0.004 & 0.34 & 0.14 & $0.70^{*}$ & 0.024 \\
\hline Glutamate release $X$ anxiety-like behavior & $-0.49^{*}$ & 0.005 & $-0.58^{*}$ & 0.007 & $-0.54^{*}$ & 0.013 & $-0.78^{*}$ & 0.007 \\
\hline Glutamate release $X$ depressive-like behavior & -0.17 & 0.36 & -0.26 & 0.26 & -0.28 & 0.22 & -0.51 & 0.13 \\
\hline Anxiety-like behavior $\times$ social memory & -0.30 & 0.11 & -0.29 & 0.21 & -0.37 & 0.10 & -0.47 & 0.16 \\
\hline Anxiety-like behavior $\times$ depressive-like behavior & 0.15 & 0.42 & 0.25 & 0.27 & 0.22 & 0.36 & 0.50 & 0.14 \\
\hline Social memory $\times$ depressive-like behavior & -0.31 & 0.08 & $-0.47^{*}$ & 0.036 & -0.37 & 0.10 & -0.40 & 0.24 \\
\hline
\end{tabular}

Data represent Pearson's correlation coefficient $(r)$ and related $p$ values. The level of significance was set at $p<0.05\left(^{*}\right)$. Veh, Vehicle; Ago, agomelatine; Flx, fluoxetine.

et al., 2013). The following factors might contribute to explaining these contrasting findings: (1) the different breeding of the animals (reared from birth in the animal facility in our study); (2) the execution of multiple behavioral tasks before the assessment of glutamate release in our study; (3) use of ventral versus total hippocampus in the two studies; and (4) the different concentrations of $\mathrm{K}^{+}$ions used to stimulate glutamate release (12 vs 15 $\mathrm{mM}$ ), resulting in different extents of depolarization-evoked release in the two studies.

So far, the pharmacological validity of the glutamatergic hypothesis of anxious/depressive disorders was mainly supported by the antidepressant activity of ketamine, which behaves as a slow NMDA receptor channel blocker (for review, see Maeng and Zarate, 2007). To date, the effects of classic antidepressants on glutamate release have been investigated either under basal conditions or in response to acute or chronic stress that induces a hyperfunction of glutamatergic neurotransmission in adult "normal" rats (Bonanno et al., 2005; Musazzi et al., 2010; Tardito et al., 2010; Reagan et al., 2012; Milanese et al., 2013). Adult animals exposed to acute or chronic stress represent a model of reactive depression or post-traumatic stress disorder. Here we were able to demonstrate an action of antidepressants on glutamatergic 
transmission in PRS rats that recapitulates the hallmark features of endogenous depression and anxiety, and are characterized by a reduction in glutamate release in the ventral hippocampus (see also Marrocco et al., 2012). Antidepressant treatment in PRS rats enhanced glutamate release without changing GABA release. This action might correct the imbalance between excitatory and inhibitory neurotransmission in the ventral hippocampus, thereby restoring cognitive functions related to stress and emotions in PRS rats (Bannerman et al., 2004; Engin and Treit, 2007; Fanselow and Dong, 2010). The evidence that chronic antidepressant treatment normalizes either the increase or the decrease in glutamate release (in normal rats exposed to stress and PRS rats, respectively) suggests that the action of antidepressants critically involves glutamatergic transmission in the hippocampus.

The precise mechanism by which antidepressants modulate the function of glutamatergic synapses in the hippocampus remains unknown. The primary mechanisms of action of fluoxetine and agomelatine may converge into a common intracellular pathway leading to a functional remodeling of glutamatergic terminals. An attractive hypothesis is that, regardless of their primary mechanisms of action, antidepressants epigenetically regulate the expression of synaptic vesicle-associated proteins at glutamatergic terminals, thereby correcting the abnormalities of glutamate released caused by different forms of stress. Epigenetic mechanisms are now considered as potential targets for antidepressant medication (Nasca et al., 2013; Vialou et al., 2013), and the possibility that these mechanisms involve synaptic vesicleassociated proteins warrants in-depth investigation. It will also be interesting to examine whether agomelatine and fluoxetine act directly on glutamatergic neurons in the ventral hippocampus or modulate glutamatergic transmission transynaptically by acting primarily on other stations of the neural circuitry underlying stress and emotion.

The use of the same animals from each group for behavioral studies and ex vivo measurements of neurotransmitter release enabled a correlation analysis between glutamate release in the ventral hippocampus and anxiety-like behavior, depressive-like behavior in the forced swim test, and social memory performance. Interestingly, the extent of glutamate release was inversely related to anxiety, and showed a positive correlation with social memory performance when rats treated with agomelatine were included in the analysis. This particular profile of correlation was expected because (1) agomelatine was highly effective in improving both anxiety-like behavior and social memory in PRS rats, and (2) reduction of anxiety has a favorable impact on social memory (Landgraf et al., 1995) by influencing the balance between reserve and explorative curiosity and improving cognitive flexibility (Blazevic et al., 2012). It is reasonable to conclude that agomelatine decreases anxiety-like behavior in PRS rats by correcting the defect of glutamate release in the ventral hippocampus, and that the improvement in social memory is a direct consequence of the anxiolytic effect. We were surprised to find no correlation between glutamate release in the ventral hippocampus and depression-like behavior in the forced swim test, as well as between anxiety- and depression-like behaviors. We suggest that anxiety and depression are two unrelated psychopathological outcomes of the neuroadaptive programming triggered by early life stress, of which only anxiety might be directly linked to a presynaptic impairment of glutamate release in the ventral hippocampus.

In conclusion, our data provide the first pharmacological validation for the "glutamatergic hypothesis" of stress-related disorders (Holden, 2003; Hashimoto, 2009; Popoli et al., 2011;
McCarthy et al., 2012) by demonstrating the action of novel and classic antidepressants in the PRS model, which replicates developmental factors involved in the etiology of anxious/depressive disorders (for review, see Krishnan and Nestler, 2010), and also has predictive and face validity as an experimental animal model of anxiety and depression in humans (Darnaudéry and Maccari, 2008). This lays the groundwork for the study of glutamate release in the ventral hippocampus in other experimental models, and in humans with anxiety and depression. We suggest that glutamatergic transmission in the ventral hippocampus, a key brain region involved in the maladaptive programming caused by early life stress, represents an attractive pharmacological target for the development of novel therapeutic strategies.

\section{References}

Baldwin DS, Lopes AT (2009) Agomelatine improves symptoms of generalised anxiety disorder. Evid Based Ment Health 2:54. CrossRef Medline

Banasr M, Soumier A, Hery M, Mocaër E, Daszuta A (2006) Agomelatine, a new antidepressant, induces regional changes in hippocampal neurogenesis. Biol Psychiatry 59:1087-1096. CrossRef Medline

Bannerman DM, Rawlins JN, McHugh SB, Deacon RM, Yee BK, Bast T, Zhang WN, Pothuizen HH, Feldon J (2004) Regional dissociations within the hippocampus - memory and anxiety. Neurosci Biobehav Rev 28:273-283. CrossRef Medline

Becker G, Kowall M (1977) Crucial role of the postnatal maternal environment in the expression of prenatal stress effects in the male rats. J Comp Physiol Psychol 91:1432-1446. CrossRef Medline

Bernard R, Kerman IA, Thompson RC, Jones EG, Bunney WE, Barchas JD, Schatzberg AF, Myers RM, Akil H, Watson SJ (2011) Altered expression of glutamate signaling, growth factor, and glia genes in the locus coeruleus of patients with major depression. Mol Psychiatry 16:634-646. CrossRef Medline

Blazevic S, Colic L, Culig L, Hranilovic D (2012) Anxiety-like behavior and cognitive flexibility in adult rats perinatally exposed to increased serotonin concentrations. Behav Brain Res 230:175-181. CrossRef Medline

Bonanno G, Giambelli R, Raiteri L, Tiraboschi E, Zappettini S, Musazzi L, Raiteri M, Racagni G, Popoli M (2005) Chronic antidepressants reduce depolarization-evoked glutamate release and protein interactions favoring formation of SNARE complex in hippocampus. J Neurosci 25:32703279. CrossRef Medline

Bradford MM (1976) A rapid and sensitive method for the quantitation of microgram quantities of protein utilizing the principle of protein-dye binding. Anal Biochem 72:248-254. Medline

Chapman RH, Stern JM (1979) Failure of severe maternal stress or ACTH during pregnancy to affect emotionality of male rat offspring: implications of litter effects for prenatal studies. Dev Psychobiol 12:255-267. CrossRef Medline

Chen G, Henter ID, Manji HK (2010) Presynaptic glutamatergic dysfunction in bipolar disorder. Biol Psychiatry 67:1007-1009. CrossRef Medline

Choudary PV, Molnar M, Evans SJ, Tomita H, Li JZ, Vawter MP, Myers RM, Bunney WE Jr, Akil H, Watson SJ, Jones EG (2005) Altered cortical glutamatergic and GABAergic signal transmission with glial involvement in depression. Proc Natl Acad Sci U S A 102:15653-15658. CrossRef Medline

Dantzer R, Bluthe RM, Koob GF, Le Moal M (1987) Modulation of social memory in male rats by neurohypophyseal peptides. Psychopharmacology (Berl) 91:363-368. Medline

Darnaudéry M, Maccari S (2008) Epigenetic programming of the stress response in male and female rats by prenatal restraint stress. Brain Res Rev 57:571-585. CrossRef Medline

de Bodinat C, Guardiola-Lemaitre B, Mocaër E, Renard P, Muñoz C, Millan MJ (2010) Agomelatine, the first melatonergic antidepressant: discovery, characterization and development. Nat Rev Drug Discov 9:628-642. CrossRef Medline

Dugovic C, Maccari S, Weibel L, Turek FW, Van Reeth O (1999) High corticosterone levels in prenatally stressed rats predict persistent paradoxical sleep alterations. J Neurosci 19:8656-8664. Medline

Dunkley PR, Jarvie PE, Heath JW, Kidd GJ, Rostas JA (1986) A rapid method for isolation of synaptosomes on Percoll gradients. Brain Res 372:115-129. CrossRef Medline 
Engin E, Treit D (2007) The role of hippocampus in anxiety: intracerebral infusion studies. Behav Pharmacol 18:365-374. CrossRef Medline

Fanselow MS, Dong HW (2010) Are the dorsal and ventral hippocampus functionally distinct structures? Neuron 65:7-19. CrossRef Medline

Garcia-Garcia AL, Elizalde N, Matrov D, Harro J, Wojcik SM, Venzala E, Ramírez MJ, Del Rio J, Tordera RM (2009) Increased vulnerability to depressive-like behavior of mice with decreased expression of VGLUT1. Biol Psychiatry 66:275-282. CrossRef Medline

Hashimoto K. Emerging role of glutamate in the pathophysiology of major depressive disorder (2009) Brain Res Rev 61:105-123. CrossRef

Holden C. Psychiatric drugs (2003) Excited by glutamate. Science 300: 1866-1868. CrossRef Medline

Isingrini E, Camus V, Le Guisquet AM, Pingaud M, Devers S, Belzung C (2010) Association between repeated unpredictable chronic mild stress (UCMS) procedures with a high fat diet: a model of fluoxetine resistance in mice. PLoS One 4:e10404. CrossRef Medline

Kasper S, Hajak G, Wulff K, Hoogendijk WJ, Montejo AL, Smeraldi E, Rybakowski JK, Quera-Salva MA, Wirz-Justice AM, Picarel-Blanchot F, Baylé FJ (2010) Efficacy of the novel antidepressant agomelatine on the circadian rest-activity cycle and depressive and anxiety symptoms in patients with major depressive disorder: a randomized, double-blind comparison with sertraline. J Clin Psychiatry 71:109-120. CrossRef Medline

Krishnan V, Nestler EJ (2010) Linking molecules to mood: new insight into the biology of depression. Am J Psychiatry 167:1305-1320. CrossRef Medline

Landgraf R, Gerstberger R, Montkowski A, Probst JC, Wotjak CT, Holsboer F, Engelmann M (1995) V1 vasopressin receptor antisense oligodeoxynucleotide into septum reduces vasopressin binding, social discrimination abilities, and anxiety-related behavior in rats. J Neurosci 15:4250-4258. Medline

Levitan MN, Papelbaum M, Nardi AE (2012) A review of preliminary observations on agomelatine in the treatment of anxiety disorders. Exp Clin Psychopharmacol 20:504-509. CrossRef Medline

Loiseau F, Le Bihan C, Hamon M, Thiébot MH (2006) Effects of melatonin and agomelatine in anxiety-related procedures in rats: interaction with diazepam. Eur Neuropsychopharmacol 16:417-428. CrossRef Medline

Maccari S, Piazza PV, Kabbaj M, Barbazanges A, Simon H, Le Moal M (1995) Adoption reverses the long-term impairment in glucocorticoid feedback induced by prenatal stress. J Neurosci 15:110-116. Medline

Maeng S, Zarate CA Jr (2007) The role of glutamate in mood disorders: results from the ketamine in major depression study and the presumed cellular mechanism underlying its antidepressant effects. Curr Psychiatry Rep 9:467-474. CrossRef Medline

Mairesse J, Silletti V, Laloux C, Zuena AR, Giovine A, Consolazione M, van Camp G, Malagodi M, Gaetani S, Cianci S, Catalani A, Mennuni G, Mazzetta A, van Reeth O, Gabriel C, Mocaër E, Nicoletti F, MorleyFletcher S, Maccari S (2013) Chronic agomelatine treatment corrects the abnormalities in the circadian rhythm of motor activity and sleep/ wake cycle induced by prenatal restraint stress in adult rats. Int J Neuropsychopharmacol 16:323-338. CrossRef Medline

Marrocco J, Mairesse J, Ngomba RT, Silletti V, Van Camp G, Bouwalerh H, Summa M, Pittaluga A, Nicoletti F, Maccari S, Morley-Fletcher S (2012) Anxiety-like behavior of prenatally stressed rats is associated with a selective reduction of glutamate release in the ventral hippocampus. J Neurosci 32:17143-17154. CrossRef Medline

McCarthy DJ, Alexander R, Smith MA, Pathak S, Kanes S, Lee CM, Sanacora G (2012) Glutamate-based depression GBD. Med Hypotheses 78:675681. CrossRef Medline

Milanese M, Tardito D, Musazzi L, Treccani G, Mallei A, Bonifacino T, Gabriel C, Mocaer E, Racagni G, Popoli M, Bonanno G (2013) Chronic treatment with agomelatine or venlafaxine reduces depolarizationevoked glutamate release from hippocampal synaptosomes. BMC Neurosci 14:75. CrossRef Medline

Millan MJ, Brocco M, Gobert A, Dekeyne A (2005) Anxiolytic properties of agomelatine, an antidepressant with melatoninergic and serotonergic properties: role of 5-HT2C receptor blockade. Psychopharmacology (Berl) 177:448-458. CrossRef Medline

Morley-Fletcher S, Darnaudery M, Koehl M, Casolini P, Van Reeth O, Maccari S (2003) Prenatal stress in rats predicts immobility behavior in the forced swim test. Effects of a chronic treatment with tianeptine. Brain Res 989:246-251. CrossRef Medline

Morley-Fletcher S, Mairesse J, Soumier A, Banasr M, Fagioli F, Gabriel C,
Mocaer E, Daszuta A, McEwen B, Nicoletti F, Maccari S (2011) Chronic agomelatine treatment corrects behavioral, cellular, and biochemical abnormalities induced by prenatal stress in rats. Psychopharmacology (Berl) 217:301-313. CrossRef Medline

Musazzi L, Milanese M, Farisello P, Zappettini S, Tardito D, Barbiero VS, Bonifacino T, Mallei A, Baldelli P, Racagni G, Raiteri M, Benfenati F, Bonanno G, Popoli M (2010) Acute stress increases depolarizationevoked glutamate release in the rat prefrontal/frontal cortex: the dampening action of antidepressants. PLoS One 5:e8566. CrossRef Medline

Musazzi L, Treccani G, Mallei A, Popoli M (2013) The action of antidepressants on the glutamate system: regulation of glutamate release and glutamate receptors. Biol Psychiatry 73:1180-1188. CrossRef Medline

Nasca C, Xenos D, Barone Y, Caruso A, Scaccianoce S, Matrisciano F, Battaglia G, Mathé AA, Pittaluga A, Lionetto L, Simmaco M, Nicoletti F (2013) L-acetylcarnitine causes rapid antidepressant effects through the epigenetic induction of mGlu2 receptors. Proc Natl Acad Sci U S A 110:48044809. CrossRef Medline

Nibuya M, Nestler EJ, Duman RS (1996) Chronic antidepressant administration increases the expression of cAMP response element binding protein (CREB) in rat hippocampus. J Neurosci 16:2365-2372. Medline

Ongür D, Jensen JE, Prescot AP, Stork C, Lundy M, Cohen BM, Renshaw PF (2008) Abnormal glutamatergic neurotransmission and neuronal-glial interactions in acute mania. Biol Psychiatry 64:718-726. CrossRef Medline

Papp M, Gruca P, Boyer PA, Mocaër E (2003) Effect of agomelatine in the chronic mild stress model of depression in the rat. Neuropsychopharmacology 28:694-703. CrossRef Medline

Papp M, Litwa E, Gruca P, Mocaër E (2006) Anxiolytic-like activity of agomelatine and melatonin in three animal models of anxiety. Behav Pharmacol 17:9-18. Medline

Popoli M, Yan Z, McEwen BS, Sanacora G (2011) The stressed synapse: the impact of stress and glucocorticoids on glutamate transmission. Nat Rev Neurosci 13:22-37. CrossRef Medline

Porsolt RD, Anton G, Blavet N, Jalfre M (1978) Behavioural despair in rats: a new model sensitive to antidepressant treatments. Eur J Pharmacol 47:379-391. CrossRef Medline

Pothion S, Bizot JC, Trovero F, Belzung C (2004) Strain differences in sucrose preference and in the consequences of unpredictable chronic mild stress. Behav Brain Res 155:135-146. CrossRef Medline

Raiteri L, Raiteri M (2000) Synaptosomes still viable after 25 years of superfusion. Neurochem Res 25:1265-1274. CrossRef Medline

Raiteri M, Angelini F, Levi G (1974) A simple apparatus for studying the release of neurotransmitters from synaptosomes. Eur J Pharmacol 25: 411-414. CrossRef Medline

Reagan LP, Reznikov LR, Evans AN, Gabriel C, Mocaër E, Fadel JR (2012) The antidepressant agomelatine inhibits stress-mediated changes in amino acid efflux in the rat hippocampus and amygdala. Brain Res 1466: 91-98. CrossRef Medline

Santarelli L, Saxe M, Gross C, Surget A, Battaglia F, Dulawa S, Weisstaub N, Lee J, Duman R, Arancio O, Belzung C, Hen R (2003) Requirement of hippocampal neurogenesis for the behavioral effects of antidepressants. Science 301:805-809. CrossRef Medline

Sommi RW, Crismon ML, Bowden CL (1987) Fluoxetine: a serotoninspecific, second-generation antidepressant. Pharmacotherapy 7:1-15. CrossRef Medline

Soumier A, Banasr M, Lortet S, Masmejean F, Bernard N, Kerkerian-Le-Goff L, Gabriel C, Millan MJ, Mocaer E, Daszuta A (2009) Mechanisms contributing to the phase-dependent regulation of neurogenesis by the novel antidepressant, agomelatine, in the adult rat hippocampus. Neuropsychopharmacology 34:2390-2403. CrossRef Medline

Stein DJ, Ahokas AA, de Bodinat C (2008) Efficacy of agomelatine in generalized anxiety disorder: a randomized, double-blind, placebocontrolled study. J Clin Psychopharmacol 28:561-566. CrossRef Medline

Stein DJ, Ahokas A, Albarran C, Olivier V, Allgulander C (2012) Agomelatine prevents relapse in generalized anxiety disorder: a 6-month randomized, double-blind, placebo-controlled discontinuation study. J Clin Psychiatry 73:1002-1008. CrossRef Medline

Stokes PE, Holtz A (1997) Fluoxetine tenth anniversary update: the progress continues. Clin Ther 19:1135-1250. CrossRef Medline

Surget A, Saxe M, Leman S, Ibarguen-Vargas Y, Chalon S, Griebel G, Hen R, Belzung C (2008) Drug-dependent requirement of hippocampal neuro- 
genesis in a model of depression and of antidepressant reversal. Biol Psychiatry 64:293-301. CrossRef Medline

Tardito D, Milanese M, Bonifacino T, Musazzi L, Grilli M, Mallei A, Mocaer E, Gabriel-Gracia C, Racagni G, Popoli M, Bonanno G (2010) Blockade of stressinduced increase of glutamate release in the rat prefrontal/frontal cortex by agomelatine involves synergy between melatonergic and 5-HT2C receptordependent pathways. BMC Neurosci 11:68. CrossRef Medline

Tordera RM, Totterdell S, Wojcik SM, Brose N, Elizalde N, Lasheras B, Del Rio J (2007) Enhanced anxiety, depressive-like behaviour and impaired recognition memory in mice with reduced expression of the vesicular glutamate transporter 1 (VGLUT1). Eur J Neurosci 25:281-290. CrossRef Medline

Tuma J, Strubbe JH, Mocaër E, Koolhaas JM (2005) Anxiolytic-like action of the antidepressant agomelatine (S 20098) after a social defeat requires the integrity of the SCN. Eur Neuropsychopharmacol 15:545-555. CrossRef Medline
Van Reeth O, Olivares E, Zhang Y, Zee PC, Mocaer E, Defrance R, Turek FW (1997) Comparative effects of a melatonin agonist on the circadian system in mice and Syrian hamsters. Brain Res 762:185-194. CrossRef Medline

Vialou V, Feng J, Robison AJ, Nestler EJ (2013) Epigenetic mechanisms of depression and antidepressant action. Annu Rev Pharmacol Toxicol 53: 59-87. CrossRef Medline

Yalcin I, Aksu F, Belzung C (2005) Effects of desipramine and tramadol in a chronic mild stress model in mice are altered by yohimbine but not by pindolol. Eur J Pharmacol 514:165-174. CrossRef Medline

Zuena AR, Mairesse J, Casolini P, Cinque C, Alemà GS, Morley-Fletcher S, Chiodi V, Spagnoli LG, Gradini R, Catalani A, Nicoletti F, Maccari S (2008) Prenatal restraint stress generates two distinct behavioral and neurochemical profiles in male and female rats. PLoS One 3:e2170. CrossRef Medline 